Illinois State University

ISU ReD: Research and eData

Theses and Dissertations

$10-9-2013$

\title{
Mark Twain and Critical Thinking in the Secondary Classroom
}

Daniel Zehr

Illinois State University, dzehr@wacohi.net

Follow this and additional works at: https://ir.library.illinoisstate.edu/etd

Part of the American Literature Commons, Education Commons, Fine Arts Commons, and the Literature in English, North America Commons

\section{Recommended Citation}

Zehr, Daniel, "Mark Twain and Critical Thinking in the Secondary Classroom" (2013). Theses and Dissertations. 50.

https://ir.library.illinoisstate.edu/etd/50

This Thesis is brought to you for free and open access by ISU ReD: Research and eData. It has been accepted for inclusion in Theses and Dissertations by an authorized administrator of ISU ReD: Research and eData. For more information, please contact ISUReD@ilstu.edu. 


\title{
MARK TWAIN AND CRITICAL THINKING \\ IN THE SECONDARY CLASSROOM
}

\author{
Daniel D. Zehr
}

41 Pages

December 2013

This qualitative study explored and evaluated the school literacy practices of high school-aged participants at the freshmen level (grade 9). It interpreted their analysis, comprehension, and critical thinking skills through an examination of confidence, abilities, and fluency through discussion and student-led dialogue. Building on previous research regarding critical thinking skills, the researcher articulated the ways in which students with varied levels of ability (grades 9-12) may be able to use their literacy learning to demonstrate critical thinking skills (multi-dimensional thinking, as opposed to linear thinking). These skills enhanced their reading fluency, comprehension, and analytical skills, and fostered an appreciation of literature and discussion that nurtured a confident, articulate understanding of Twain and his texts. This may in turn bridge the gap to other texts of various levels of complexity and reading levels. Fostering critical thinking skills, and emphasizing the valuable and credible nature of these skills through normal classroom discourse led to more confident, literate, capable student learners who not only experience the joy of reading, but an increase in critical thinking for an increase in literary fluency and competency. 


\title{
MARK TWAIN AND CRITICAL THINKING \\ IN THE SECONDARY CLASSROOM
}

DANIEL D. ZEHR

\author{
A Thesis Submitted in Partial \\ Fulfillment of the Requirements \\ for the Degree of \\ MASTER OF CURRICULUM AND INSTRUCTION \\ School of Teaching and Learning \\ ILLINOIS STATE UNIVERSITY
}


MARK TWAIN AND CRITICAL THINKING

IN THE SECONDARY CLASSROOM

DANIEL D. ZEHR

COMMITTEE MEMBERS

Ellis Hurd, Chair

Roberta Trites

Thomas Lucey 


\section{ACKNOWLEDGEMENTS}

I would like to thank Dr. Ellis Hurd for his patience, guidance and support during this long process, and for his efforts to make me a better, more effective writer. I would also like to thank Dr. Thomas Lucey for giving me the original idea of using critical thinking in my classroom, and for introducing me to a whole new world of pedagogy. None of my educational experiences at the university level would be complete, however, without the guidance, encouragement, and friendship of Dr. Roberta Trites, and I am grateful. I would also like to thank Henry Sweets, Executive Director of the Mark Twain Boyhood Home and Museum, and Dr. Cindy Lovell, Executive Director of the Mark Twain House and Museum for helping me to become a full-fledged "Twainiac", and reintroducing me to his world.

This thesis is dedicated to the two strongest women I have ever known, my mother, Linda, and my wife, Deanna. My mother taught me perseverance and passion, and has supported me every day of my life. This is affectionately dedicated to Deanna, who has sustained me during many long days and nights of writing, empowered me to achieve success, and is my continual example of love, intelligence, and all that is beauty. She also gave me my three boys, Peyton, Parker, and Mason, which show me every day the joys life has to offer. 


\section{CONTENTS}

ACKNOWLEDGEMENTS $\quad$ i

$\begin{array}{ll}\text { CONTENTS } & \text { ii }\end{array}$

CHAPTER

I. INTRODUCTION 1

II. LITERATURE REVIEW

Introduction $\quad 5$

The Nature and Development of Critical Thinking and the Progression of Learning 5

The Difficulties in Teaching Critical Thinking $\quad 8$

Instructional Methods Designed to Promote Critical Thinking $\quad 10$

The Benefits of Twain and Critical Thinking in High School Literature $\quad 11$

The Benefits of The Adventures of Tom Sawyer to Promote Critical Thinking $\quad 13$

$\begin{array}{ll}\text { Research Questions } & 15\end{array}$

$\begin{array}{ll}\text { III. METHODOLOGY } & 17\end{array}$

$\begin{array}{lr}\text { Setting } & 17\end{array}$

$\begin{array}{ll}\text { Participants } & 18\end{array}$

$\begin{array}{ll}\text { Data Collection and Analysis } & 18\end{array}$

$\begin{array}{ll}\text { IV. RESULTS } & 21\end{array}$

$\begin{array}{ll}\text { Assertiveness } & 23\end{array}$

$\begin{array}{ll}\text { Reluctance } & 24\end{array}$

Interviews with Reluctant Students $\quad 27$

A Progression of Collaborative Ideas 28

Research Questions Revisited 31 
$\begin{array}{ll}\text { Implications } & 34\end{array}$

$\begin{array}{ll}\text { REFERENCES } & 37\end{array}$

$\begin{array}{ll}\text { APPENDIX A } & 40\end{array}$ 


\section{CHAPTER I}

\section{INTRODUCTION}

The researcher seeks to analyze and reinforce the importance and relevance of critical thinking in the classroom through dynamic teaching, group interaction, and collaborative learning. The topic of study for this research is centered on critical thinking at the high school level, and will demonstrate the benefits of developing critical thinking skills (both developing critical thinking questions for discussion, as well as responding to them) to increase fluency, confidence, and rhetorical skills. Research indicates that these skills will enhance student learning, and facilitate an interest in knowledge that many students may not even realize was lying dormant. This study will demonstrate how teaching Mark Twain's The Adventures of Tom Sawyer, with an emphasis on critical thinking skills, can lead freshmen to experience multi-dimensional thinking.

To accomplish this goal, the work of Mark Twain (more specifically, The Adventures of Tom Sawyer) is used to develop critical thinking. Mark Twain is a credible writer and his texts provide many challenges which serve to further growing literary fluency learned through this study. These devices may even break down barriers of learning and encourage students to take their experiences to other myriad texts

When Mark Twain created the character of Tom Sawyer in his beloved The Adventures of Tom Sawyer, he proceeded to comment on societal norms, as well as 
injustice and to advocate against the cruelty of humankind against one another. The Adventures of Tom Sawyer features an intriguing narrative that had been overlooked as merely a beloved children's book, but respected scholars, such as Clark (2003) have demonstrated that this is not the case anymore (Clark, 2003). Twain uses rhetoric skillfully to blend satire and realism in order to allow for a reflection of the culture of the late 1800 's, and also illustrates the cruelty inflicted on Native American Indians through the character of Injun Joe. This rhetorical style is pertinent to a development of increasing critical thinking amongst students, and the insights provided through the study helped support this.

In Sawyer, Twain had woven a novel with complex themes under the guise of lighthearted, boyhood whimsy. The themes include social justice, social class, race, religion, and education. This avenue introduces critical thinking concepts into each student's learning, as the character helps disarm the apathy and ambivalence that can be challenging to neutralize in freshmen. This apathy and ambivalence towards reading that a majority of my students have expressed can be challenging to overcome, and can greatly debilitate future academic achievement, success, and confidence. It is this attitude that prompted a need for this study.

Tom Sawyer has (and is) typically thought of as a children's book by some scholars and readers alike, but this does not seem to be an accurate analytical perspective (Clark, 2003). Rather, Twain punctuates his novel with rhetorical delights that brilliantly emphasize and critiques societal and cultural norms, as well as of religion and race. While the tone of Tom Sawyer may not always appear immediately pertinent in its denunciation of the foibles of society, that does not take away from its importance to the 
literary canon. In fact, this leads to the legitimacy of the novel as a method for improving critical thinking among high school students.

The researcher is the only instructor at Community High School that actively teaches Twain's work. Some colleagues have not given Twain the canonical importance that this researcher believes Twain deserves. This seeming denial of legitimacy in the canon is a primary reason for many to disagree with The Adventures of Tom Sawyer as a novel of weight and significance, especially in its examination of race (Lee, 2003). However, there is research to demonstrate that this is not the case (Robinson, 1984; Trites, 2007).

This study self-demonstrates that a critical reading of Twain's works leads to a development of critical thinking through discussion that cannot be placated or replaced by other famous pieces of literature. Twain's place in the canon should be irrevocable, and demonstrated this through the pedagogical approach of attempting to advance each student's independent and dependent learning through critical thinking questions and concepts, student-led discussions, and reflective reading strategies.

Twain's texts offer a variety of levels of difficulty for students at the freshmen level (vocabulary, comprehension, challenging themes) that will offer opportunities for learning beyond what is normally taught at the Secondary level. Students should do much more with a text than answer a few study guide questions and move on to a project or essay, which was how I was taught at the Secondary level. While these basic assignments have their particular merit, it is important for students to see that the level of critical thinking and analysis that goes into composing a piece of literature is beneficial and exciting for a student learner, once he or she starts to disseminate the myriad ways in 
which analysis through discussion helps to open doors to learning that were previously not considered (or in some cases, even approached).

Critical thinking (multi-dimensional thinking as opposed to linear thinking) through developing outside the box thinking is essential to a classroom culture that prepares students for the many challenges they will encounter throughout their lives, and learning to see beyond a cursory reading of Twain will provide that opportunity. This study will help provide the setting for learning to take place that will enhance and strengthen the level of analysis that may not appear plausible at first. A number of students may resist the idea of looking deeply into texts, but this reticence leads to opportunity, as the habits that are gleaned through daily, student-led discussion increase confidence, as well as competence through practice, presentation, and participation.

This study has the potential to nurture a healthy learning environment. This learning environment will lead to an increase in a better understanding of each student's literary fluency and competence. As a result, this learning environment will lend itself to understanding and interpreting texts at a higher level. Using Mark Twain's The Adventures of Tom Sawyer to promote critical thinking in the secondary classroom will help reinforce Twain's place in the literary canon, and continue to foster multidimensional thinking that will empower high school students to increase confidence, abilities, and fluency. 


\section{CHAPTER II \\ LITERATURE REVIEW}

\section{Introduction}

In this Literature Review, the following topics are explored: the Nature and Development of Critical Thinking and the Progression of Learning, the Difficulties in Teaching Critical Thinking, Instructional Methods Designed to Promote Critical Thinking, the Benefits of Twain and Critical Thinking in High School Literature, and the Benefits of The Adventures of Tom Sawyer to Promote Critical Thinking. Each of the topics addresses key elements of the study that blend together to demonstrate how critical thinking at the secondary level is enhanced through an examination of The Adventures of Tom Sawyer. Mark Twain's classic was chosen due to the unique blend of accessibility and complexity that this study examines in depth. How does teaching Mark Twain's The Adventures of Tom Sawyer, with an emphasis on critical thinking skills, lead freshmen to experience multi-dimensional thinking? The literature helps to bring this to light.

\section{The Nature and Development of Critical Thinking and the Progression of Learning}

Discussions that do not lead to critical thinking can severely hamper independent learning. To encourage authentic, independent learning, students have to be nurtured to provide something new to the discussion on a regular basis. Kliebard (2004) illustrates this when he discusses the work of John Dewey. He explains, "Dewey once recalled that Plato defined a slave as one who had none of his own ideas but was always expressing 
those of someone else" (p. 69). As an educator, this is an alarming statement with which others may agree (McCrae, 2011; Oenwald, 2010).

Clearly, critical thinking is not a new construct. McCrae explains, "fourth century philosopher Augustine of Hippo rejected the notion that pupils should merely learn whatever their teacher thinks" (p. 128). Students need to learn to develop their own intrinsic analysis to fully engage with the material they are examining (Choorapanthiyil, 2007). This self-assessment leads to a natural progression for the student, as he or she will be able to draw upon daily interaction amongst the class to start to comprehend what critical thinking questions are, and how best to interpret and analyze them, and can become a form of self-mental discipline. This breaks down barriers and obstacles towards the text, so that students will develop a meaningful interaction, free of doubt and angst that can occur when reading a challenging work. It is this monitoring and management of student critical thinking that enhances learning, as Walberg (2011) state, “Skills were seen as important, but the learner's monitoring and management of them had priority, as though the explicit teaching functions of planning, allocating time, and reviewing were partly transferred to the learner" (p. 99).

This is further emphasized when Choy and Cheah (2009) state: ... teachers who have an apt and positive perception of critical thinking, and feel equipped to incorporate it in their instruction may actually do so because they believe that critical thinking will help students learn, and by so doing it will lead to positive outcomes. (as cited in Enabulele, 2011, p. 12) 
These critical thinking skills encourage student empowerment and help to inspire selfactualized learning. The discussions and level of complexity achieved throughout the critical thinking discussions help to ignite an enthusiasm for learning that helps to encourage interest in an examination of other works.

It is intriguing to explore how students perceive learning in this manner, as most seem to enjoy the idea of looking beyond the surface of a text, but it may not always appear self-evident, until it begins to germinate amongst the classroom setting. Steffen (2011) examined, among other things, “... how students in this high school perceived themselves as learners of critical thinking skills" (p. 3). Students look positively at critical thinking, and seem to believe it is incorporated into their daily psyche (p. 4). This attitude is something that comes to fruition when developed through practice, as this study demonstrates. Enthusiasm reverberates once these skills are practiced, and become contagious once fluency is sculpted into a daily feature of the classroom setting.

It is prudent to mention the work of Bloom's Taxonomy when exploring the hierarchy of thinking and analysis (Bloom, 1956). Bloom's work discusses building on factual knowledge, and builds towards more abstract ways of thinking that encourage an exploration of a text and building towards more analytical concepts and ways of thinking. This rationale helps build confidence and repetition, and continues to enable growth. This growth is reached through students being allowed to take the lead, and self-actualize their thought process.

When educators do not allow for students to take their own lead in learning and classroom discussion, there is no opportunity for individualized growth. Rupani and Bhutto (2011) reveal in their study the disconcerting notion that specific things absent in 
their observations of certain teachers included, "proper[ly] motivating the learners, presenting the content, and appropriate evaluating techniques for teaching a concept or lesson" (p. 123). They further demonstrate how important it is to involve reflection and analysis into pedagogy, and how it can be simple to overlook, particularly if a teacher defines an ideal classroom as "silent"” (p. 123). Clearly, this is damaging, but some teachers have been reluctant, perhaps, in part, to some of the challenges present in teaching critical thinking.

\section{The Difficulties in Teaching Critical Thinking}

The emphasis on developing critical thinking needs to be emphasized in the classroom. Oenwald (2010) explains, "If a student's aesthetic imagination is not given a voice, it diminishes both the student's possibility of a deeper intellectual enrichment and the possibility of his sharing and creating meaning within the community of the classroom" (p. 187). Once this voice is established, it allows for building confidence and fluency in each student's abilities in discussion (p. 18). Most students (particularly at the freshmen level) are reticent at the outset, as most are worried about "being wrong" or "looking dumb", as initial comments revealed through a free write given to classes. The challenge is to get students to believe in what they are saying, and look beyond the text.

But it is not always easy, particularly when trying to get students to look outside the surface of what a text is initially offering through plot, characters, themes, and other basic tropes of literature. Building confidence through examples and discussion lends itself to this, and helps to break down walls students have put up, particularly when looking at texts such as Twain's. Critical thinking dictates that students look for meaning and analysis, based on many different factors. This is particularly of value when 
discussing critical thinking components of language in Twain's texts, and what that requires for critical thinking. Barlowe (2010) discusses Mark Twain and the issue of language and critical thinking in regards to Adventures of Huckleberry Finn (Barlowe, 2010). The article addresses Twain's importance, as far as advocating for black people. This lends itself to critical discussions of how an author and his background impact writing. It also tends to promote empathy in students, which is useful in fostering a learning community.

This is why students need to find a connectivity with the material that impacts them, which can promote self-discovery. Discerning a book with a more profound meaning that many students are familiar with or experience through media in its many forms has an exciting impact on students and student learning. For instance, Trites (2007) examines Twain's presentation of Huckleberry Finn's famous moral crisis when she states:

Huck's moral crisis, on the other hand, is necessitated by a national crisis of morals, which brings me to my third point about growth in Huckleberry Finn: the novel is as much about the need for a nation to mature as it is about a boy's need to mature. (pp. 41-42)

Critical thinking is paramount to evaluating Huck's famous internal struggle, and there is evidence throughout Twain's works that supplements this belief. In conjunction with this, each student is going through different stages of social and moral development at the high school level, and the study of this through discussion and critical thinking helps to bridge gaps between student apathy and student interest, and ventures into moral issues that students experience. 
The potential is most certainly there, as each examination of his myriad texts presents examples of the potential for critical thinking that leads to learning and growth for students (Chapman, 2009). When presenting an argument for Twain's characters as a discussion of morality, in terms of distance from the idea of good verses bad, the reader should instead focus on a commentary of the gray in society, as well as the "ridiculous standards of nineteenth-century children's literature" and what is valued or lauded (p. 16). This opens the door to trying to figure out how character is interpreted through actions, as well as how societal views and pressures dictate what is thought of as acceptable or rebellious, as the case may be. These incidents, which challenge social norms and cultural models, are excellent opportunities for students to engage in Twain's work, and fan a proverbial flame of an interest in looking at a text as a gateway to insightful, intelligent knowledge and discussion.

\section{Instructional Methods Designed to Promote Critical Thinking}

In demonstrating the scope of Twain's work, critical thinking through discussion helps ignite confidence, comprehension, and a passion for learning. Perrin (2009) looks at Mark Twain within the scope of John Dewey for analysis. He states, "Dewey's philosophy and practice offer an interesting correlative with the thread of educational ideas throughout the work of Twain, suggesting that Twain's educational ideas are both modern and congruent with those of Dewey" (p. 90). It is precisely this modern ideological construct that will bring students out of apathy and reluctance, and into finding common ground with the material. That is where the buy in comes into play for students. 
This buy-in promotes an attentive nature that encourages critical thinking. Buenaseda-Saludo (2012) discusses critical thinking, in relation to John Dewey. She states, "We pay attention to fiction that will potentially engage students in a constant process of ethical judgment, depicting characters and situations that call for our moral evaluation" (p. iv). Twain's characters feature dynamic attributes that engage students' moral and ethical approach to life (Trites, 2007). Naturally, getting students to engage in what they are learning leads to a more productive classroom environmental society and relating to the material through intriguing characters helps to bring that concept to fruition. In order to do that, however, each student has to learn how to create a critical thinking question, as well as how to reply to one.

It is a thought-provoking concept that students are essentially thinking about thinking, but can be perplexing to translate, at first. In principle, Noden and Moss (1994) explain, "Metacognitive questions engage students' minds in reflection on process and represent an essential strategy for empowering students to learn independently" (p. 505). It is this type of independent thinking that fosters knowledge and growth, which is further fostered through discussion and observation. In terms of Twain, examining the character of Tom Sawyer and his interplay with the people of St. Petersburg helps students to grow in metacognition through analysis, much like Tom Sawyer starts to grow through his fictional interactions.

\section{The Benefits of Twain and Critical Thinking in High School Literature}

Mark Twain is a master of literature, with profound characters, pragmatic and challenging ethical dilemmas, and weighty issues of race, gender, class, and identity. Each one of these topics is fodder for critical thinking discussions that Twain provides in 
a palpable, invigorating way, although some educators have chosen to ignore this, simply thinking of Twain as a writer of children's books (Robinson, 1984). Children's literature exceeds most literature in terms of structure, character development, and critical thematic material, many use the term as a pejorative (Clark, 2003).

Using the work of Mark Twain to help stimulate critical thinking is an important part of this study. Lindsey (2012) talks about how Twain created an "American voice", and led to a new understanding of self-reliance and more profound constructs of character. Twain was a life-long student of American culture, and this passion helps to, once more, bridge a gap, and relate students to Twain's writing (pp. 2-3). This is an illustration of Twain's ability to examine concepts that lead to critical thinking, and are beneficial to classroom rhetoric and discussion.

Addressing these concepts should start at the freshman level, to facilitate strong classroom habits. Smith (2009) discusses teaching and assessing critical thinking in a freshmen language arts classroom. He discusses thinking critically when he states, "The ability to think critically has to do with the disposition for a person to consider multiple perspectives, anticipate opposing viewpoints, validate cross-cultural differences, and to make dialectic decisions" (p. 10). For some students, critical thinking may be out of their comfort zone, as well as unnatural for them (Smith, 2009), but this is precisely why it is so important in the context of classroom practicum. Literature forces the reader to look at different scenarios from different perspectives. It also allows for critical debates that open the mind to marked concepts from a student's original designs. Again, this promotes and encourages empathy, which tends to translate towards an enthusiasm for 
learning and confidence in what the student is doing to improve comprehension and fluency.

Students subscribing to Twain, and their relating to his characters still has to take place, and the relationships students can have with his characters may help promote that beneficial relationship. This is further explained by Bourland (2010), who believes,

"Twain and Percy as authors of projects of regenerating agency advance the case that art has the capacity to be instructive and illuminating as part of our moral discourses in ways that theory cannot replicate" (p. iii). The use of Mark Twain in the classroom can feature insights and a sense of intelligence exhibited through character that helps to look inside ourselves as agents of intelligence and character. The agency exhibited through Twain's characters provides a lens through which individuals can analyze and interpret his or her own actions and motivation.

\section{The Benefits of The Adventures of Tom Sawyer to Promote Critical Thinking}

A cursory reading of the novel may seem to indict Twain as bigoted in his treatment of Native Americans, but further reflection reveals that Twain is actually pointing out the horrific ways that Native Americans are not only treated in a majority of literature of the time, but also shows the despicable nature of societal bigotry as well. The character of Injun Joe represents the hatred heaped upon Native American people, while also illuminating the paradoxical views in which civilized people examine their own prejudices (Kalter, 2011). Mark Twain's rhetorical strategy is not to be overlooked in regards to The Adventures of Tom Sawyer, and to dismiss this important work as just a children's novel is to ignore Twain's brilliance and creativity in examining cultural and societal normatives of the time. 
Lee (2003) discusses how Mark Twain uses the character of Tom Sawyer to create an idea that things are not always as they seem. Lee explains, "Twain essentially turns the old conventions of Good and Bad Boys on its head and then comes up with a completely new definition ..." (p. 25). The Adventures of Tom Sawyer presents a number of ethical and moral dilemmas that ask the reader to debate Tom's motivation, as well as his decision making skills, which provide for fascinating discussion among freshmen, as the study will demonstrate. Lee examines the nature of the ethical dilemmas that Tom Sawyer is continually forced to reckon with, and how that illustrates literary brilliance that leads to much critical thinking.

There are occasions, however, where some harbor a tendency to cast a reluctant eye towards this literary classic. Robinson (1984) notices, "Indeed, it is not unusual to find professional students of American history and literature who admit that they have not gone back to Tom Sawyer since they first read it-or since it was first read to them-as children" (p. 1). This appears to be a measure of how the book is both loved and misunderstood, as far as its literary relevance. This also may be why it is not taught at the secondary level as frequently as other American classics. Far from just being a children's book, Tom Sawyer is much more of an indicator of Twain's genius: he weaves a novel with complex themes under the guise of lighthearted, boyhood whimsy, and Robinson supports this notion repeatedly.

Clark (2003) also demonstrates how Twain's The Adventures of Tom Sawyer has more historical support than others have suggested. In fact, children's literature has the same power and importance as adult literature. Clark states, "The fact is that children's literature almost always has to address adults as well as children ..." (p. 64). Through a 
detailed look at The Adventures of Tom Sawyer and Adventures of Huckleberry Finn, Clark (2003) reinforces Tom Sawyer's place in the canon, as well as the power the narrative has to illuminate insights into human behavior and psychology, which are essential to an examination of critical thinking. High school students are more apt to explore critical thinking concepts when they believe they have a personal investment, and discussions over any novel seem to demonstrate a willingness to empathize with the story's characters once they understood they could invest in those character's journeys. In order to address the issue of teaching Mark Twain's The Adventures of Tom Sawyer, with an emphasis on critical thinking skills, in order lead freshmen to experience multi-dimensional thinking, and to examine the literacy practices of high school-aged participants, the researcher explored the following questions. These questions helped to lead to a clearer understanding of the information obtained, as this study examined the role of critical thinking questions in the secondary classroom through a study of The Adventures of Tom Sawyer.

\section{Research Questions}

The research questions were:

1. Are students' initial fears or reticence in regards to complex Twain texts parlayed throughout a unit emphasizing critical thinking and student/teacher modeling?

2. Does the formation of critical thinking questions enhance student comprehension, literary fluency, and overall enjoyment of a Twain text? 
3. Does the analysis of critical thinking questions enable richer discussions, and as a result, lend itself towards a more competent, confident, attentive reader and learner? 


\section{CHAPTER III METHODOLOGY}

Qualitative research is rich in its ability to collect and analyze data, particularly when relating to the places and people where observation is the key component (Creswell, 2005). This particular qualitative design used a case study that focused on the participants in the researcher's classroom (Tesch, 1990). The case study was appropriate, due to the participants involved, and the analytical approach used to synthesize the data collected.

\section{Setting}

The target high school was located in Central Illinois, in a small suburban town. This small town of approximately 12,000 people lies just outside a city of nearly 200,000 people. Within this area was one high school with three public feeder schools, and one private feeder school. The town has a minority population (including White, Black, Hispanic, Asian, etc.) of about 7\% (Illinois State Board of Education eReport Card, 2013). The median family income is approximately $\$ 50,000$.

The high school involved in this study had approximately 1,200 students which were primarily middle-class, with $17 \%$ of the student population on free and reduced lunch (Illinois State Board of Education eReport Card, 2013). Of particular interest, one of the feeder districts had a significantly higher incidence of poverty. Most of the 
students came from a double income household, while the feeder district

previously mentioned had a greater number of single parent households.

\section{Participants}

Participants were drawn from three different English-1-freshman classes. The researcher was the only instructor involved in the study. 75 students were asked to participate in the study of whom the majority were male. Students ranged in age from 13-15 years, depending on when each started his or her academic career. There were 35 male and 22 female student participants. I recruited all of my freshmen students to participate in the study, and 57/75 agreed, for a 76\% partiipation rate. Note: A case of ten students were used illustrative of data and used for discussion. Each student's name has been given an alias, in order to protect his or her identity.

\section{Data Collection and Analysis}

From April to June of 2013, data were collected. This data were collected through structured observation of classroom discussions, student interviews, and coding and analysis of various data. Through this process, an organization of specific patterns emerged during the study (Creswell, 2005, p. 238). A spreadsheet was used to monitor how many times each student participated in discussion, and through this data, it was

apparent who spoke consistently, and who increased his or her amount of participation as the study progressed.

The assignment and rubric used for this study (appendix A) feature a focus on a few key topics (five total). Each student was required to lead one class discussion and prepare three critical thinking questions per student (six total per group). The students 
were tasked with asking questions throughout their lesson, in addition to basic plot questions to keep the conversation going during class.

A schedule was used for specific calendar days and chapters provided. This allowed the students to select partners for work. After signing up for the chapters and days, questions pertaining to the assignment were discussed. I led class discussions for two days, demonstrating my thought processes as I modeled critical thinking questions and prompt analysis and rhetoric. I asked the students a critical thinking question, such as, "How does Tom Sawyer's ability to manipulate his peers to do his work for him an example of Twain commenting on societal norms and peer pressure?" Once students responded to this question, I asked them to explain why the question provided was a critical thinking question. Student responses varied from "It wasn't obvious right away" to "It has more than one answer". The metacognitive process helped to form future critical thinking questions throughout the unit. Based on this model, student-groups were expected to continue accordingly for their own discussions.

It is important to note that while each student was required to lead a class discussion, this meant that for the rest of the unit, each student had to participate at least three times a class period, in order to get participation points. Participation for the purposes of this study meant answering questions on the novel, thereby showing preparation and knowledge of the assignment. To ensure that each student talked no more than three times in a period, three poker chips were distributed to each student not leading discussion each day. This served as a type of reminder, whereby each student had to self-regulate if they either talked too much (as far as dominating discussion), or did not participate enough to gain points for the day's lesson. Not only were the 
questions being asked useful in this regard, but seeing how the students responded, and entered into dialogue with the class was beneficial (Perrin, 2009).

Initially, I wrote down specific comments that seemed insightful and reflected learning, but did not put down who the individual was that spoke. It was important to provide examples of the class discussions, comments, and questions, and this had a strong effect on the analysis done for the study, and led to coding themes. When reporting on the discussions and comments of the students, I made notes that provided an alias for each student, so as to protect his or her identity, as per the Permission/Assent forms dictates. I then coded the data into three patterns, in order to organize and structure the finding into a more pragmatic application. This allowed for an interpretation based on how much analysis was each student willing to make, students thinking about the characters in the story, literary themes in the story, and the relationships and social structures that developed and co-mingled as a result. Essentially, the comments were separated into different categories for analysis. These categories led to the different patterns that are listed below. A considerable amount of time was spent coding data, which led to the development of three patterns. 


\section{CHAPTER IV}

\section{RESULTS}

The results stemmed from a detailed examination of the coded data mentioned above, and led to the development of three patterns. The patterns were focused on students' willingness or hesitation in explaining their theories, and were predicated on class preparation and a rudimentary understanding of the text. The responses were the result of student led class discussion and field notes, teacher observation, and student interviews.

The patterns were:

1. Vacillating analysis reluctance from students

2. Increased examination of characters in the story beyond surface value

3. Willingness for increased theme complexity in the story for higher sophistication of understanding.

These patterns were used to interpret how students developed critical thinking as a process, and how, in conjunction with this ideology, showed more of an interest in an analytical reading of Twain. The patterns helped to reveal certain tendencies and inclinations that students gravitated towards during their own analysis. Once the data was divided into the three patterns, further analysis led to a more concentrated, 
consolidated picture of the overall results of the study (Tesch, 1990). Analysis helped to support the theory that a concentrated study of Twain's work and a focus on critical thinking perpetuated more sophisticated responses and rhetoric.

Contained within these three patterns were nuances over how students reacted to the complexities of critical thinking and textual analysis in Tom Sawyer. A more thorough investigation revealed that the three patterns were redefined into two themes: 1) assertiveness and 2) reluctance. Within these themes, a lot of the personality traits that students previously exhibited showed themselves more prominently.

A select few students were more likely to raise their hands right away, and run out of chips within the first ten minutes of class. Subsequently, they continued to try and participate in discussions once they were out of chips, to further demonstrate their knowledge. Students who were more apt to be shy and reserved were even more reluctant, as it became apparent that these individuals were concerned that their responses would be "wrong". Initial observations over the data indicate this may have been shyness, while, for others, it was apathy.

When it came for me to explain how to create a critical thinking question, it was a much more challenging process for students, as these types of questions are much more reflective; critical thinking questions involve metacognition which enhances the thinking process (Noden \& Moss, 1994). Metacognition lends itself to a much richer type of discussion, as students look beyond the text, and into independent thinking. The results of critical thinking are beneficial, as Noden and Moss (1994) state, "Metacognitive questions engage students' minds in reflection on process and represent an essential strategy for empowering students to learn independently," (p. 505). 


\section{Assertiveness}

The first theme was assertiveness. Insightful comments revealed themselves among the majority of students. Early on, I proposed the following question to participants. The following is a dialogue exchange between me and some students.

Instructor: How would you best describe critical thinking questions to those of us who are still trying to figure it out?

Luke: You can take critical thinking questions literally, but that's just one way to look at it.

Lois: Thinking outside the box and exploring other options.

Harrison: Critical thinking questions lead to different questions.

Assertive students in this setting proved their firm, emphatic drive through a combination of repetition, timing, and volume. Once discussions started, assertive students shot their hands into the air, as soon as the first question was asked, and positioned themselves so that their faces lined up directly with the instructor. This continued daily, as students of this particular ilk loudly proclaimed that they knew each answer, sometimes with an “Oh!” or a similar onamatopoeia to proclaim they held the knowledge within.

Perhaps the biggest testament to assertiveness gleaned during discussions was the poker chips used during each class discussion. As previously stated, each student was given three poker chips, indicating that they had three opportunities for providing an answer during discussion. Some students would answer their three questions, and then appeared to drift away, and no longer were engaged in the discussion. However, assertive students raised their hands anyway, desperate to continue to participate. 
When I would explain to each of them that they had answered their three questions for the day, and met the requirements, I would receive comments such as, "I know the answer" "Can I have more chips?” and/or "Can I answer if he/she doesn't?" I noticed an almost insatiable desire to partake of participation among some students, which stemmed from an enthusiasm for discussion that I had not previously noticed during discussions that did not have critical thinking as the main focus. It seemed that the paradigm shift towards critical thinking promoted a strong appetite for learning. It also seemed that Tom Sawyer's machinations through St. Petersburg lent themselves to a rhetorical enthusiasm that had not previously surfaced when studying other works. All but three students appeared critically engaged.

Getting students to realize that this is my goal as an educator is essential; critical thinking skills encourage student empowerment and help to inspire self-actualized learning. Choy and Cheah (2009) state:

... teachers who have an apt and positive perception of critical thinking, and feel equipped to incorporate it in their instruction may actually do so because they believe that critical thinking will help students learn, and by so doing it will lead to positive outcomes. (as cited in Enabulele, 2011, p. 12)

I found this to be true in previous classroom discussions, and the level of dialogue increased dramatically as the unit went on.

\section{Reluctance}

The second theme which emerged was reluctance. The questions the students came up with at the beginning of the unit were acceptable, but much more guidance was 
needed on my part, as some questions were basic, lacking in depth. I reminded my classes every day that critical thinking questions are not yes or no or fact-based; they ask readers to look beyond the text. The following is a dialogue exchange between me and some students, which demonstrates students beginning to theorize with one another, as they asked:

Clark: Basically, critical thinking questions ask you to question everything, right?

Instructor: Absolutely.

Olivia: Are you supposed to ask about symbols and things like that?

Instructor: That would be a good start. Try and evaluate different things you notice.

Questions about symbols began to manifest themselves regularly ("What did the characters in Chapter 8 that Tom wanted to be like symbolize?"). The students previously mentioned that were worried about being right started to assert themselves, mostly out of frustration and concern for their grade. A few asked:

Olivia: How do you know if it's right? My answers sound stupid.

Instructor: No they don't. You may not be used to looking at things in this way. As long as you back up your answers with evidence from the book, it is critical thinking.

Sam: So, it has to be deep.

Instructor: That is actually a good way to look at it. It has to make you think more deeply than you have before.

Sam: I don't get this. 
Instructor: You're doing just fine. Be patient with yourself, and I have a feeling it will click before you know it.

Harrison: Tom Sawyer opposes any power over him, just like Mark Twain when he was growing up.

Instructor: Awesome! That sounds pretty smart to me.

Luke: So we should ask why characters do certain things, and what it means?

Instructor: Exactly. That would be a great start.

The other members of the class heard this, and it seemed to take root. The evidence was apparent in how the students started to get more confident, and began to discover the level of analysis I hoped for them to achieve. The strongest indicator of this occurred when examining the spreadsheet used to collect data. The students that previously participated once or twice a week were now participating three times a day. This demonstrated an increase in confidence not previously seen in other units given in class.

I also reinforced the concept they began to understand by stopping class discussion and saying things like, "Why is this good place to begin critical thinking?" Students would explain things like why characters do certain things, and trying to figure out what motivates them became useful in our discussions. Some students pointed out that since critical thinking has multiple interpretations, you can look at things from many different perspectives. Questions started to go beyond basic plot and character themes, and began to explore Twain's purpose and social commentary (Bourland, 2010). 


\section{Interviews with Reluctant Students}

Despite the best of intentions, Sam, Elaine, and Olivia (aliases) were still reluctant to engage in discussion. It became apparent that some investigation into this needed to be done. I had three separate interviews with the participants, to discover why they were not forthright with their responses.

Sam freely admitted that reading was not a course of action he enjoyed. He told me that he reads, but it takes too long, and he doesn't understand what is going on. When asked if he read the entire assigned chapters, he admitted that he read "most of it." This was followed by asking him why he did not read the entire section. Sam said it didn't make sense, so he just skimmed it. When asked if he thought discussion would be more beneficial if he knew what was going on, and was better prepared, he said he thought so.

Olivia admitted that she was shy, and did not like talking in front of people. I explained that her participation would help her do well in class, and that she had intelligent things to say, based on the times when she did participate. She said that did not matter to her, and she just did not want to speak in class. This presented a quandary, in which I decided Olivia might need additional support.

When asked what would help her get engaged in discussion, and receive participation points, we mutually agreed that she would write a one page (front to back handwritten or one page typed and double-spaced) summary of the assigned reading chapter, followed by 2 critical thinking questions she thought of during the reading. Fortunately, this seemed to help, as her comments and questions were insightful and pertinent to conversation, and while she did not directly participate in discussion, her 
writing reflected an attentive student with much to say, who was not willing to share her thoughts with her peers.

Elaine was emblematic of a few other students that participated in the study: Elaine did not want to be wrong, and was afraid to look like she was not intelligent. She explained, “I don't get what's going on sometimes, or when I want to say an answer, somebody already says it. I don't know what to say." She also mentioned that she doesn't always remember what she read, and that makes it confusing. At this point, I suggested writing down bullet points of what she read while she was actually reading, which would help jog her memory during discussion. At first, this did not happen, but once she realized that her grade was reflecting her preparation for class, I noticed her putting her notes on her desk during discussion, and participation started to go back up. She was more engaged in class, and seemed more content with her answers as a result.

\section{A Progression of Collaborative Ideas}

As the themes of assertiveness and reluctance emerged, more insightful comments began to consistently manifest themselves during discussion. This became clearer when specific topics were being discussed. One of the students asked the question, "What did the destruction of the camp symbolize for the boys when they were on Jackson Island?" Various answers included:

Mary: That they were free and could do whatever they wanted.

Instructor: That is one strong possibility. Anyone else?

Elaine: That they didn't have to listen to authority anymore, and could just be free.

Instructor: True. Why was this important? 
Elaine: Because they were tired of being told what to do, and wanted to stop being in trouble all the time.

Instructor: Ok. That makes sense. What about from a literary, critical perspective?

Bruce: The destruction of the camp symbolized destruction of their lives and order.

Instructor: Excellent! Why do you say that?

Bruce: Because they do not have to be responsible for anything but themselves, and are in their own society now.

Sam: That's deep.

Another example of this occurred at the end of the novel, when Tom Sawyer and Becky Thatcher are trapped in the cave with Injun Joe. One student brought up an interesting theme in the literature. The student asked the class:

Leia: Do you think Twain had Tom Sawyer in the cave for three days because of Jesus?

Most of the students looked around at one another, or at their desks, because most seemed at a loss. This caused some discomfort, whether it was because of a religious theme, it seemed too far-fetched, or because some students had no knowledge of the biblical New Testament. An explanation of why this might hold true was explored.

Elaine: What does that mean?

Leia: It's because Jesus rose from the dead on the third day. It's because of religion. 
Instructor: Mark Twain might have been amused by your analysis, as he had a love/hate relationship with Christianity most of his life. Do you think Mark Twain was purposely making a connection, and if so, was it for satire, or something else?

Elaine: What's satire?

Clark: Did Mark Twain believe in God?

This led to a discussion of the author's background and beliefs, and I saw some fascinating changes in many of my students, as far as the growth of the learning community, more engagement and participation, and more willingness to explore deeper, more analytical approaches to the text (Joudeh, 2009; Oenwald, 2010).

Student motivation increased, as the reluctant learners started to develop their own intrinsic analytical voice, and began to consistently participate in discussion (Choorapanthiyil, 2007). Participation became contagious, as these reluctant students began more invested in the classroom dynamic being experienced through this study, and assertive students repeated their enthusiasm in class (Steffen, 2011). There is not much (if any) current research on these patterns of assertiveness and reluctance, but perhaps more can be revealed through further study and application.

It became transparent that more wide-ranging answers were beginning to manifest themselves as a result of dialogue, as students realized that they could go much deeper through discussion and analysis. Niall McCrae explains (2011), "Educationalists have long maintained that the purpose of teaching extends beyond imparting fact and theory. Rather than passively accepting received wisdom, students are encouraged to think for themselves," (p. 128). I began to see the more confident and assertive students begin to 
come up with intriguing theories that had not been previously explored in discussion (Smith, 2009).

Perhaps even more encouraging was how the classes, as a whole would encourage those students who were either not confident in their answers, or could not remember what they had read. There were moments when it was a struggle to get each of my students to participate three times a day, and I had to find a way to encourage their curiosity, increase their effort, and build confidence. Some students needed more encouragement and support, while others just wanted to get their points for the day, and then disengage, while others seemed to enjoy looking at things critically, and wanted to answer every question.

\section{Research Questions Revisited}

Are students' initial fears or reticence in regards to complex Twain texts parlayed throughout a unit emphasizing critical thinking and student/teacher modeling?

Students' initial fears and/or reticence in regards to complex Twain texts was mixed, as the study further emphasized assertive students to a more confident level, and brought reluctant students up to a more competent and interactive role within the class. However, no students I would classify as reluctant fully transitioned to an assertive place of rhetoric, despite the success that each one had throughout the discussions and conversations with me and their peers. I would attribute this to social angst ("I don't want to be wrong") and peer pressure; most students will not change their comfort zone dramatically, despite some academic and individual success. However, there was some personal growth, as even the most reluctant of students would at least make eye contact with his or her peers, and many were more conversational as the study progressed. The 
school year was nearing an end, so it seems safe to presume that success in discussion (getting positive feedback, finding insights into the book, etc.) encouraged growth, as no other experiences throughout the school year promoted as much of a change in participation.

Does the formation of critical thinking questions enhance student comprehension, literary fluency, and overall enjoyment of a Twain text?

Forming critical thinking questions did enhance student comprehension, literary fluency, and overall enjoyment of a Twain text through this study. The level of complexity that matured and progressed as we made our way through the novel as a class was palpable based on student comments, observations, and interactions. As stated in section 4 , the analytical prowess that students achieved through questioning one another (examining the significance of numbers, finding Biblical themes, analyzing symbols) and discussion was fascinating, and the excitement in each student's face when they would discover something new and different (as far as they were concerned) was inspiring (Kalter, 2011; Lee, 2003). Through this new insight brought enjoyment, as students were heard during discussion (as well as before and after class) saying things like, "That was pretty interesting", "Tom Sawyer is legit", and "Discussing books like this is actually pretty cool". As stated above, no other lessons or activities during the course of the school year promoted and encouraged as much involvement and participation as this study.

Does the analysis of critical thinking questions enable richer discussions, and as a result, lend itself towards a more competent, confident, attentive reader and learner? 
Finally, the analysis of critical thinking questions does enable richer discussions that lend themselves to more competent, confident, attentive readers, but this seems to primarily be the case when students are fully engaged in the lesson, and are more interested in participation and analysis. Those students who started out assertive, or who grew to become more on that end of the spectrum were more likely to come up with a more literary way of examining the text. Those students who attempted to receive full credit for each discussion were just as likely to want to participate more after they had exhausted their supply of chips, thereby promoting a more attentive, confident, competent reader and learner. Those students who were more likely to exhibit a reluctant posture would occasionally slip into even more reticence, especially if they were afraid their answers would be incorrect. Regardless of these observations, the level of rhetoric and discourse was much more insightful and engaging, and critical thinking was the reason that such levels of engagement were achieved. 


\section{CHAPTER V \\ CONCLUSIONS AND IMPLICATIONS}

\section{Implications}

It is my hope that students will walk away from this study with the realization that there is much more to reading than words on a page. A discussion on The Adventures of Tom Sawyer will promote critical thinking, provided that the student is open to different interpretations, and has prepared by reading the assigned sections of the text. This study revealed that students found success through insight and achieved personal growth through the rhetorical strategies gleaned during course discussion. It was truly invigorating as an educator to see enthusiasm increase for Tom Sawyer and his camaraderie with Huckleberry Finn.

The findings of this study helped to reinforce the benefits of critical thinking in the secondary classroom, but they also helped to reveal the strengths of The Adventures of Tom Sawyer in the secondary classroom as an important device for promoting fluency, confidence, and rhetorical skills. Several conclusions can be made regarding balancing critical thinking and discussion. Perhaps the main point of interest is that critical thinking helps students to elucidate their speculative nature in a formal setting that helps them draw on a reflective, analytical method of reading and discussion. 
Several students' comments featured growth, as far as the level of analysis through discussion; the discussions evolved as the journey through Twain's novel progressed. Students who demonstrated reluctance at the beginning of the study started to demonstrate confidence as they witness other students shed the cloak of insecurity to gain understanding of what critical thinking means, in terms of analysis and discussion. Sometimes this prompting came from motivation via personal achievement, collaborative dialog and guidance from parents and the instructor (due to grades slipping through a lack of interaction with the class during discussion), or from observing their peers go through similar moments of personal growth.

Using Mark Twain's The Adventures of Tom Sawyer to promote critical thinking in the secondary classroom was beneficial, particularly when encouraging students to look beyond the surface of the text for analysis and discussion. This study demonstrates the benefits of critical thinking to encourage independent thinking, while at the same time fostering a sense of community where students learn from one another through analysis, discussion, and debate. This was demonstrated through how students exhibited either assertiveness or reluctance with the amount of participation in the study. These themes were supported in the literature and research done by Kalter (2011), Lee (2003), McCrae (2011), Steffen (2011), among others.

Overall, students learned to think critically when examining Mark Twain, and noticed that there is more to The Adventures of Tom Sawyer than just a classic book that some of them read when they were younger. In fact, the rhetorical strategies that students discovered through discussion and debate helped to fuel a curiosity in deciphering the 
meaning of a particular passage or section that would have been ignored or gone unnoticed, if not for the classroom dynamic experienced during this study.

The implications, particularly for those of us in the field of English, reveal that Twain's novel, as well as that of his other works, speak to high school students in much the same fashion as other great authors. Twain's works provide a unique opportunity, due to Tom Sawyer's escapades, that draws students in, and allow for them to discover messages of race, religion, societal norms, and class structure that were initially overlooked (Robinson, 1984). This is due to a stigma since debunked, thanks to the power of children's literature to address these concepts in powerful ways (Clark, 2003). Opening the classroom to Mark Twain is a powerful way to have students think critically and develop rhetorical strategies that expand each student's literary horizon.

I have been able to apply my love of Mark Twain's novel The Adventures of Tom Sawyer to demonstrate these concepts that are fundamental to my beliefs as an educator and lifelong learner. These ideas can be applied to many different novels or fields of study, but Twain's masterpiece emphasizes the human element, as well as the foibles and pitfalls that many students will encounter throughout their lives (Clark, 2003). The particular degree to which they encounter societal problems will vary, but critical thinking, compassion, and working positively within communities are certainly skills that will serve them throughout their lives, and, hopefully, become attitudes that are contagious among their peers. 


\section{REFERENCES}

Barlow, D. (2010). The teachers' lounge. Education Digest, 76(4), 65.

Bloom B. S. (1956). Taxonomy of Educational Objectives, Handbook I: The Cognitive Domain. New York: David McKay Co Inc. as cited in file:///D:/bloom.html

Bourland, L. L. (2010). Deep in the heart: Mark Twain and Walker Percy as authors of agency. (Ph.D., The University of Alabama). ProQuest Dissertations and Theses, . (851894736).

Buenaseda-Saludo, M. A. L. (2012). A Deweyan-based curriculum for teaching ethical inquiry in the language arts. (Ed.D., Montclair State University). ProQuest Dissertations and Theses, . (1010625174).

Champman, V. J. (2009). Mark Twain and the bad boy genre. (M.A., University of Central Missouri). ProQuest Dissertations and Theses, . (305069177).

Choorapanthiyil, M. J. (2007). How international teaching assistants conceptualize teaching higher order thinking: A grounded theory approach. (Ph.D., Indiana State University). ProQuest Dissertations and Theses, . (304851726).

Clark, B. L. (2003). Kiddie lit: The cultural construction of children's literature in America. Baltimore, MD: John Hopkins UP.

Creswell, J. W. (2005). Educational research: planning, conducting, and evaluating quantitative and qualitative research ( $2^{\text {nd }}$ ed.). Upper Saddle River, NY: Pearson Prentice Hall.

Enabulele, A. (2011). Critical thinking in secondary language arts: Teacher perceptions and relevant strategies. Online Submission). Online Submission,

I.S.B.E. eReport Card Public Site. (2012). community high school. [Data file]. Retrieved from http://webprod.isbe.net/ereportcard/publicsite/getReport.aspx?year=2012\&code $* * *$

Joudeh, J. L. S. (2009). Hoax literature: Reading Edgar Allan Poe, Herman Melville, and Mark Twain. (Ph.D., Yale University). ProQuest Dissertations and Theses,. (305041618).

Kalter, S. (2011). A Savagist abroad: anti-colonial theory and the quiet violence in Twain's western oeuvre. Texas Studies in Literature and Language Spring 53.1, 26-113. 
Kliebard, H. (2004). The struggle for the American curriculum (3rd ed.). New York, NY: Routledge Farmer.

Lee, D. B. (2003). That "rascal" Tom Sawyer: Mark Twain's call for ethics. (M.A., California State University, Dominguez Hills). ProQuest Dissertations and Theses,. (305272398).

Lindsey, L. L. (2012). "One's-self I sing": The theme of individualism as a part of the American experience in the works of Mark Twain, Ernest Hemingway, and Jack Kerouac. (M.A., Oklahoma State University). ProQuest Dissertations and Theses, . (1024285769).

McCrae, N. (2011). Nurturing critical thinking and academic freedom in the 21st century university. International Journal of Teaching and Learning in Higher Education, 23(1), 128-134.

Noddings, N. (2011). Contemporary issues in curriculum (A. Ornstein, E. Pajak, \& S. Ornstein, Eds., 5th ed.). Boston, MA: Pearson. (Original work published 1995)

Noden, H., \& Moss, B. (1994). Perceiving discussion as eskimos perceive snow (professional development). Reading Teacher, 47(6), 504-06.

Odenwald, K. (2010). Transforming liberal education through the imagination: Criticalcreative thinking in higher education curriculum and pedagogy. (Ph.D., City University of New York). ProQuest Dissertations and Theses, . (305185666).

Perrin, D. J. (2009). Mark Twain, John Dewey, and the image of the teacher: A case for the interpretive study of narratives within educational discourse. (Ed.D., Northern Illinois University). ProQuest Dissertations and Theses, . (304970364).

Rupani, C., \& Bhutto, M. (2011). Evaluation of existing teaching learning process of bloom's taxonomy. International Journal Of Academic Research In Business \& Social Sciences, 1119-128.

Robinson, F. G. (1984). Social play and bad faith in the adventures of tom sawyer. Nineteenth-Century Fiction, 39(1), 1-24.

Smith, H. A. (2009). Critical thinking in the secondary language arts classroom. (M.A.E., Pacific Lutheran University). ProQuest Dissertations and Theses, . (305182386).

Steffen, C. (2011). Perceptions of how teachers perceive their teaching of critical thinking skills and how students perceive their learning of critical thinking skills. (Ed.D., Missouri Baptist University). ProQuest Dissertations and Theses, . (911792256).

Tesch, R. (1990). Qualitative research: Analysis types and software tools. Bristol, PA: The Falmer Press. 
Trites, R. S. (2007). Twain, Alcott, and the birth of the adolescent reform novel. Iowa City: University of Iowa Press.

Twain, M. (2010). Adventures of Huckleberry Finn (S. Fisher-Fishkin, Ed.). New York, NY: Oxford. (Original work published 1884)

Twain, M. (2010). The adventures of Tom Sawyer Finn (S. Fisher-Fishkin, Ed.). New York, NY: Oxford. (Original work published 1876) 
APPENDIX A

Name:

\section{English One}

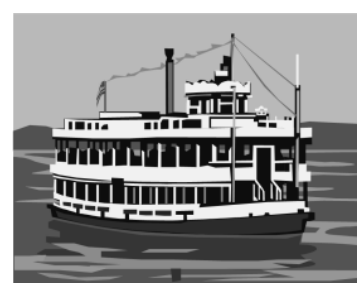

\section{The Adventures of Tom Sawyer Guided Discussion Guidelines}

\section{0 points}

For this assignment, you and a partner will be asked to lead a class discussion of two chapters of the novel The Adventures of Tom Sawyer by Mark Twain. To receive full credit for the assignment, you must read the assigned chapters, and be prepared to lead the class in discussion. The following items should be included in every discussion:

1. Full and complete knowledge of the assigned chapters you are responsible for.

2. A review of the chapters read (THIS IS NOT YOU GIVING THE

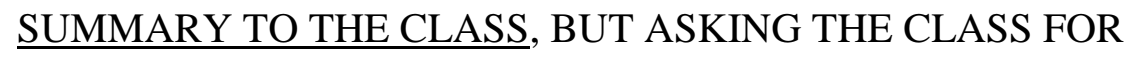
HELP!)

3. Three higher level thinking questions per student (six total per group); these questions are not fact-based or yes/no questions, but questions that ask us to analyze, interpret, or evaluate higher level meaning in the book.

4. Highlights of what you think is most important or significant to the chapters assigned. 
5. You MUST be ready to lead discussion when your group of two is asked to present. There are NO LATE GRADES for this assignment. Failure to be ready will result in a zero out of one hundred.

Full and complete knowledge of the assigned chapters you are responsible for.

(20 points)

A review of the chapters read (THIS IS NOT YOU GIVING THE SUMMARY

TO THE CLASS, BUT ASKING THE CLASS FOR HELP!) (20 points)

Three higher level thinking questions per student (six total per group); these

questions are not fact-based or yes/no questions, but questions that ask us to analyze, interpret, or evaluate higher level meaning in the book. (30 points)

Highlights of what you think is most important or significant to the chapters assigned. (15 points)

Confidence, preparation, and knowledge is demonstrated throughout the

presentation. (15 points)

Total (100 points) 